\title{
Optimizing the strength of the Bourdon effect by varying the triangle arrangement
}

\author{
Frédéric Devinck $^{1} \cdot$ Christophe Quaireau $^{1}$ \\ Accepted: 7 September 2021 / Published online: 5 October 2021 \\ (C) The Psychonomic Society, Inc. 2021
}

\begin{abstract}
The Bourdon illusion refers to the perceived bentness of the straight collinear edges when two right-angled triangles are placed apex to apex. We studied this illusion using a cancellation method. In the first of three experiments, we manipulated the apex angle, with six different angles ranging from $4^{\circ}$ to $45^{\circ}$. Results indicated that the Bourdon illusion is strongest when the angle is around $12^{\circ}$. In the second experiment, we compared four scalene triangles with a right-angled triangle. The angular shift was most salient when the shape corresponded to a right-angled triangle. In the third experiment, the patterns were created by varying the size of one right-angled triangle while holding the size of the second right-angled triangle constant. Results indicated that the Bourdon illusion was strongest when both right-angled triangles were of equal size. Our data suggest that the Bourdon illusion depends critically upon the specific arrangement of shapes in the display.
\end{abstract}

Keywords Bourdon illusion · Angle perception · Shape perception $\cdot$ Geometrical illusion

\section{Introduction}

The Bourdon illusion occurs when two right-angled triangles are placed apex to apex so that the sides opposite the hypotenuse are collinear (ABC in Fig. 1a). Under these conditions, this perfectly straight edge appears to bend in the same direction as the opposite edges (DBE in Fig. 1a). This effect is stronger in subjective contours than in real contours (Walker \& Shank, 1987; Walker \& Shank, 1988a, 1988b; Wenderoth et al., 1990).

This illusion was originally but briefly described by Bourdon (1902) in a horizontal version. To our knowledge, he did not systematically study this effect, probably because it was negligible in the original version. In the first experimental investigation of the Bourdon illusion, Rozvany and Day (1980) showed that its strength depends critically on the orientation of the pattern, with results indicating that the illusion is strongest when the whole pattern is tilted about $22.5^{\circ}$ from a vertical axis passing through its center (see Fig. 1b), and is far weaker when the whole pattern is either vertical or at an angle of $45^{\circ}$ from the vertical axis. Similar results have been found for different mirrored orientations (Verstijnen \& van

Frédéric Devinck

frederic.devinck@univ-rennes2.fr

1 Univ. Rennes, LP3C, EA 1285, 35000 Rennes, France
Leeuwen, 1998). Studies of the Bourdon illusion have typically examined the stimulus configuration that produces it. For example, the strongest illusion is produced when the internal apical angles are equal to $12.5^{\circ}$ (see Fig. 1b) (Rozvany \& Day, 1980). It should be noted that the Bourdon illusion also occurs in haptic mode, with similar parameters (Day, 1990). Other findings suggest that the illusory effect increases when a small gap is inserted between the apices of the two right-angled triangles (Day et al., 1990; Wenderoth \& O'Connor, 1987a, 1987b).

The Bourdon illusion has been observed with a solid figure like that shown in Fig. 1a, but the bentness effect persists when the right-angled triangles are formed by lines (Rozvany \& Day, 1980). Its strength increases as the thickness of the lines increases, until it is similar to that of a solid figure (Walker \& Shank, 1988a). The illusion tends to disappear when the right-angled triangles are replaced by outlines of triangles where the short sides ( $\mathrm{AD}$ and $\mathrm{CE}$ in Fig. 1a) are missing, resulting in a nonsolid figure (Rozvany \& Day, 1980; Wenderoth \& O'Connor, 1987a). This is consistent with the fact that a solid right-angled triangle displayed against a white background is needed to create the full illusion.

The impact of triangle orientation on the Bourdon illusion has been extensively tested, with most researchers showing that a specific oblique orientation creates the strongest illusion, and a horizontal or vertical orientation the weakest one 
(a)

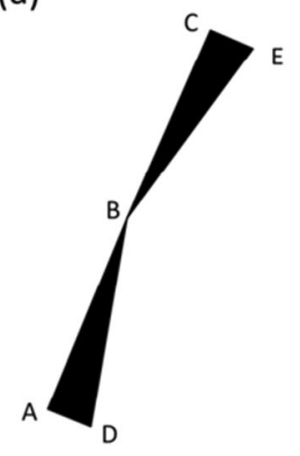

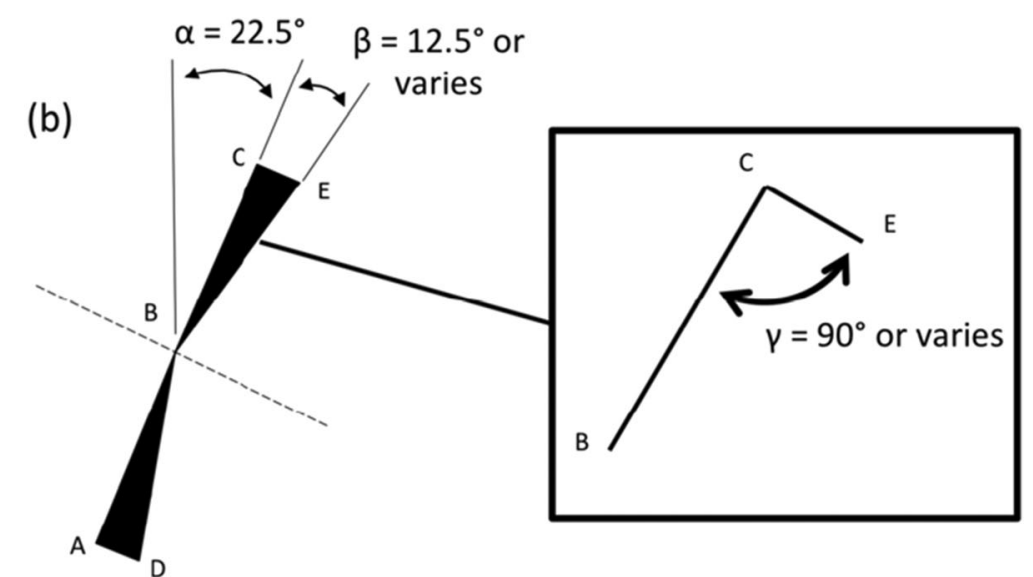

Fig. 1 Example of the Bourdon illusion. a The edges $\mathrm{AB}$ and $\mathrm{BC}$ are collinear, but appear to bend in the same direction as the chevron formed by the arms of the angle DBE. b Here, $\alpha$ refers to the orientation of the long axis of the figure relative to the vertical axis, $\beta$ refers to the internal apical angles of the figure, and $\gamma$ corresponds to the right angles. In our

(Rozvany \& Day, 1980; Verstijnen \& van Leeuwen, 1998; Wenderoth \& O'Connor, 1987a). However, although the right-angled triangle is known to be an important contributor to the illusion, the impact of the triangle shape has not yet been systematically explored. We therefore conducted three experiments in which the Bourdon illusion was studied with different triangle shapes. The aim of the first experiment was to directly test the strength of the Bourdon illusion as a function of apical angles. When the internal apical angle $\beta$ (see Fig. 1b) increased, the shape changed from a scalene triangle to an isosceles triangle. This involved the use of a cancellation task, and was a partial replication of earlier findings. In the second experiment, we investigated the strength of the Bourdon illusion using different scalene triangles. Here, the apical angle $\beta$ did not change, whereas the angle $\gamma$ (right angle in the original version; see Figs. 1b and 3) varied from an acute to an obtuse angle. In the third and final experiment, we studied how the strength of the Bourdon illusion varied when the size of one right-angled triangle was manipulated, but that of the other right-angled triangle was held constant (see Fig. 5).

\section{Experiment 1}

\section{Method}

\section{Observers}

We recruited 19 psychology undergraduates (age range: 1825 years) from Rennes University as our observers. All had normal or corrected-to-normal visual acuity, and were naïve to the purpose of the experiment. Like the two subsequent experiments, Experiment 1 was conducted in accordance with the principles of the Declaration of Helsinki.

study, angle $\alpha$ was systematically equal to $22.5^{\circ}$. In the first experiment, apex angle $\beta$ values ranged from $4^{\circ}$ to $45^{\circ}$. In the second experiment, we manipulated the angle $\gamma$ so that its values ranged from $45^{\circ}$ to $135^{\circ}$. The dashed line indicates the direction of possible adjustments to edges $\mathrm{AB}$ and $\mathrm{BC}$

\section{Apparatus}

A PC was used to display the stimuli on a 22-in. CRT monitor (NEC MultiSync FP2141SB) driven by a ViSaGe graphic board with a color resolution of 14 bits per gun (Cambridge Research Systems, Rochester, UK). The experimental software was written to generate the stimuli, control the stimulus presentation, and collect responses in Matlab 7.9 (MathWorks, http://mathworks.com), using the CRS Toolbox extensions. The monitor was calibrated using an OptiCal photometer with the calibration routines of Cambridge Research Systems. Observers viewed the screen from a distance of $80 \mathrm{~cm}$, with their head stabilized by a chin rest. Both eyes were used for viewing. Participants used a Cedrus response box (RB-530) to record their responses. The experiment was performed in a dark room.

\section{Stimuli}

Observers viewed two right-angled triangles connected by their apices, similar to those shown in Fig. 1a. All the figures were dark $\left(\mathrm{x}=0.30, \mathrm{y}=0.45 ; \mathrm{Y}=1.03 \mathrm{~cd} / \mathrm{m}^{2}\right)$, displayed against a neutral gray background $(\mathrm{x}=0.29, \mathrm{y}=0.32 ; \mathrm{Y}=$ $60.32 \mathrm{~cd} / \mathrm{m}^{2}$ ).

In accordance with previous studies (Rozvany \& Day, 1980; Verstijnen \& van Leeuwen, 1998), the figures were oriented at an angle of $22.5^{\circ}$ from the vertical axis (see angle $\alpha$ in Figs. $1 b$ and $\mathrm{c}$ ), to maximize the Bourdon illusion. The stimuli were displayed in the center of the screen. Each triangle had an $\mathrm{AB} / \mathrm{BC}$ length of approximately $6.4^{\circ}$.

There were six values of angle $\beta$ : $4^{\circ}, 8^{\circ}, 12^{\circ}, 23^{\circ}, 34^{\circ}$, and $45^{\circ}$ (see Fig. 1b). It should be noted that the $12^{\circ}$ angle formed a right-angled triangle similar to those used in previous studies 
(Rozvany \& Day, 1980; Verstijnen \& van Leeuwen, 1998), whereas the $45^{\circ}$ angle formed an isosceles triangle.

\section{Procedure}

Prior to the experiment, observers familiarized themselves with the screen for $3 \mathrm{~min}$. They were then asked to simultaneously adjust two edges ( $\mathrm{AB}$ and $\mathrm{BC}$ in Fig. 1) in a series of increments until they appeared collinear (cancellation task), by pressing the appropriate buttons on a response box. The method was as follows: we determined a line (see the dashed line in Fig. 1b) that ran perpendicular to the AC line and passed through point $\mathrm{B}(y=0.404, x+167.03)$. Participants could simultaneously adjust the edges $(\mathrm{AB}$ and $\mathrm{BC})$ in small increments (approximately 0.5 arcmin) in both directions defined by the dashed line. At the beginning of each trial, the initial position of the apex coordinates (point B in Fig. 1) was randomly picked from the line within the range of $-5^{\circ}$ to $5^{\circ}$.

This sequence was repeated until the observer deemed that the adjustment was satisfactory and pressed the central button on the response box. There was then a 1-s pause before a new trial started. Each observer completed ten trials in each angle $\beta$ condition, making a total of 60 trials, presented in random order. There was an initial practice block of three trials. The experimental session only started when the observers felt at ease with the task, otherwise they went through another practice session.

\section{Results}

Illusion strength was measured as the difference in degrees (angular error) between the apparent (mean cancellation adjustment) and actual collinearity of the two edges. If the cancellation adjustment was identical to the coordinates of the $\mathrm{AC}$ line, then the angular error would be zero. This would mean that observers did not compensate for the illusory effect. However, if the value of the cancellation adjustment differed from the coordinates of the $\mathrm{AC}$ line, the angular error would be greater or less than zero. This would mean that observers compensated for the illusory effect by moving the stimulus edges in the opposite direction. It should be noted that a positive value corresponded to an adjustment toward the top lefthand corner, and a negative value to an adjustment toward the bottom righthand corner. The mean angular errors for the six values of angle $\beta$ are plotted in Fig. 2.

The angular error increased as the angle $\beta$ increased until the latter was equal to $12^{\circ}$, beyond which the angular error decreased. The greatest adjustment $\left(1.83^{\circ}\right)$ was therefore made when the angle $\beta$ was $12^{\circ}$. Smaller adjustments $\left(0.17^{\circ}\right.$ and $\left.1.12^{\circ}\right)$ were required for an angle $\beta$ of $4^{\circ}$ and $8^{\circ}$. Results were relatively symmetrical on both sides of the $12^{\circ}$ angle. Thus, the adjustments were around $1.03^{\circ}$ when the angle $\beta$ was $23^{\circ}$, and $0.05^{\circ}$ for angle $\beta$ of $34^{\circ}$. When the angle $\beta$ was $45^{\circ}$, the angular error was $-0.23^{\circ}$.

This pattern was confirmed by a repeated-measures analysis of variance (ANOVA). An analysis of angular error for angle $\beta\left(4^{\circ} \times\right.$
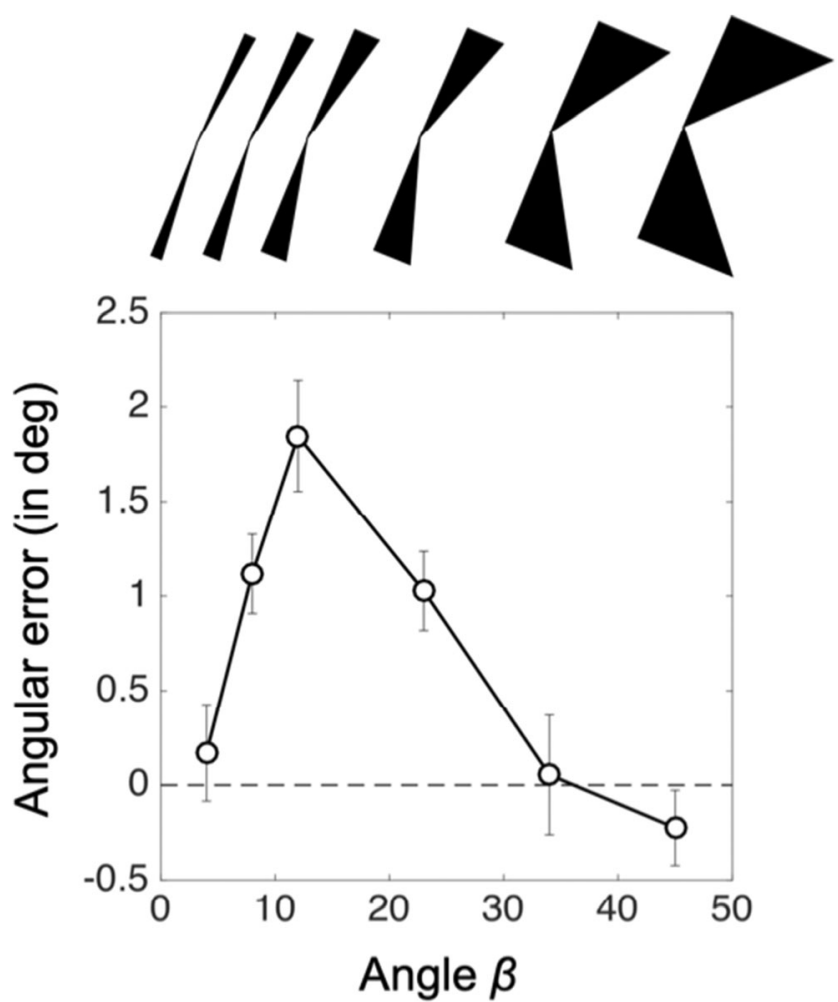

Fig. 2 Mean cancellation adjustments in degrees as a function of the internal apical angle $\beta$ (Experiment 1). The dashed line indicates the expected response when $\mathrm{AB}$ and $\mathrm{BC}$ are collinear. Error bars are $\pm 1 S E M$

$\left.8^{\circ} \times 12^{\circ} \times 23^{\circ} \times 34^{\circ} \times 45^{\circ}\right)$ yielded a significant effect, $F(5,940)=$ 113.261, $p<.001, \eta_{\mathrm{G}}^{2}=0.306, \eta_{\mathrm{p}}^{2}=0.377$. Post hoc $t$ tests with Holm-Bonferroni correction for multiple comparisons are presented in Table 1. Results indicated significant differences between the angle $\beta$ of $12^{\circ}$ and the other five conditions (Holm-Bonferroni correction, $p<0.001$ for five tests). Interestingly, no significant differences were found between angles $4^{\circ}$ and $34^{\circ}$ (HolmBonferroni correction, $p>0.5$ ) or between angle $8^{\circ}$ compared to an angle $\beta$ of $23^{\circ}$ (Holm-Bonferroni correction, $p>0.5$ ). These comparisons also revealed significant differences between all other conditions (Holm-Bonferroni correction, $p<.02$ for eight tests). We concluded that the Bourdon illusion is strongest when the angle $\beta$ is around $12^{\circ}$.

\section{Experiment 2}

\section{Methods}

\section{Observers}

We recruited 20 different psychology undergraduates aged 18-25 years as observers for the second experiment. All had normal visual acuity, and all were naïve to the purpose of the experiment. This second experiment was conducted in accordance with the Declaration of Helsinki. 
Table 1 Summary of multiple comparisons in Experiment 1

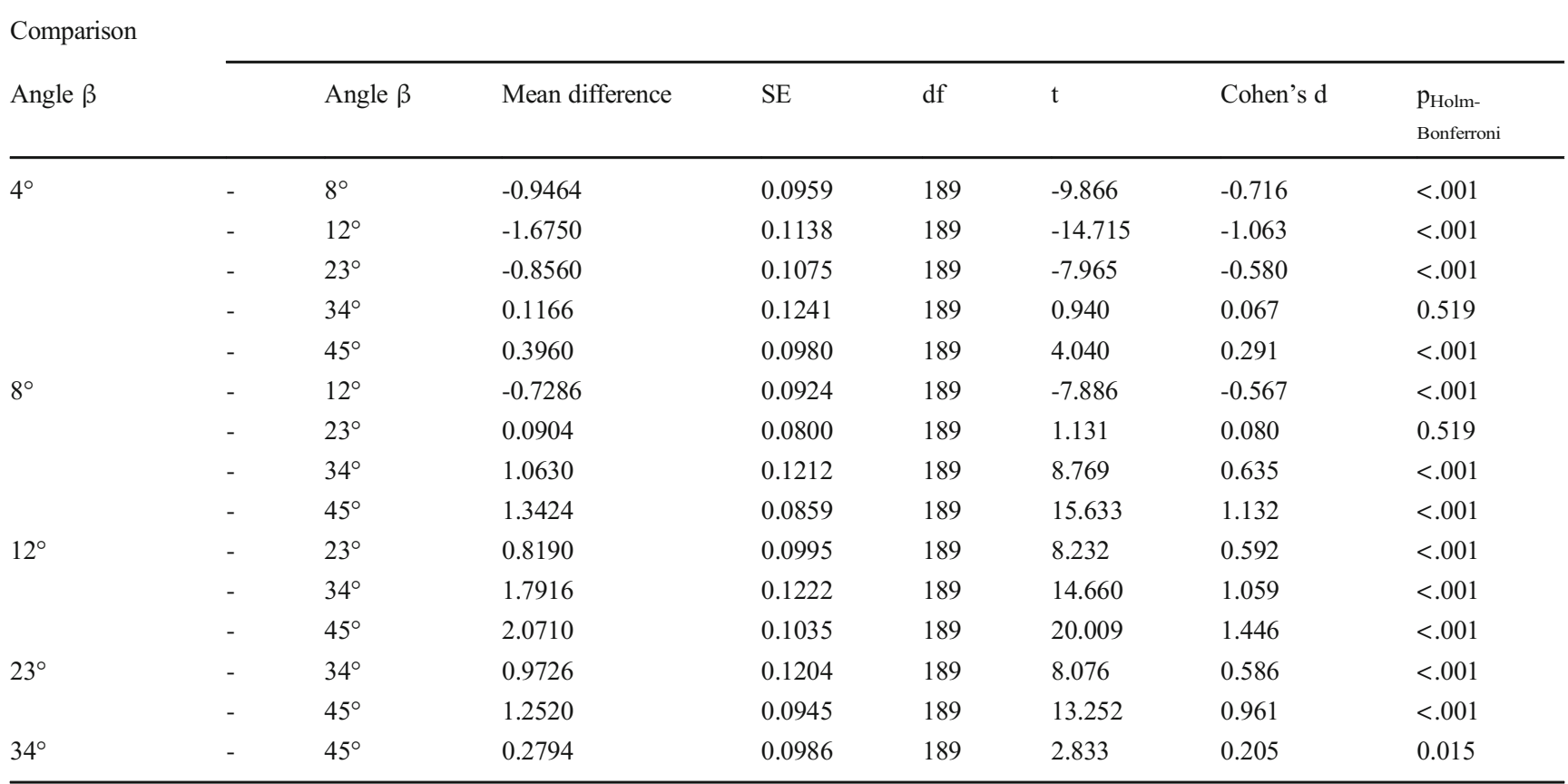

\section{Apparatus}

The same apparatus was used as in Experiment 1.

\section{Stimuli}

Figures were made up of two right-angled triangles connected by their apices. These triangles were displayed in black ( $\mathrm{x}=$ $0.30, \mathrm{y}=0.45 ; \mathrm{Y}=1.03 \mathrm{~cd} / \mathrm{m}^{2}$ ) against a neutral gray background $\left(\mathrm{x}=0.29, \mathrm{y}=0.32 ; \mathrm{Y}=60.32 \mathrm{~cd} / \mathrm{m}^{2}\right)$. The ABD $/ \mathrm{CBE}$ apex angle was systematically $12.5^{\circ}$ (see angle $\beta$ in Fig. 1), and the vertical orientation of the figure was $22.5^{\circ}$ (angle $\alpha$ in Fig. 1). These values had produced the strongest illusions in previous studies (Rozvany \& Day, 1980; Verstijnen \& van Leeuwen, 1998). In the present experiment, the triangles were displayed with five different angle $\gamma$ values, ranging from $4^{\circ}$ to $135^{\circ}$ in steps of $22.5^{\circ}$ (see Fig. 1b). Figure 3 shows the stimuli used in this experiment. It should be noted that in one condition, there was an angle of $90^{\circ}$, corresponding to a rightangled triangle (type of triangle used in the first experiment).

\section{Procedure}

The procedure was identical to that used in Experiment 1. There were a few minutes of dark adaptation prior to the experiment, and practice trials preceded the data collection. Each observer performed ten trials in each $\gamma$ angle condition, making a total of 50 trials, presented in random order each time.

\section{Results}

We calculated the mean angular error for each condition (see Fig. 4) as the difference between the mean cancellation adjustment made by each observer and the coordinates of the AC line (see Fig. 1b). The results of the cancellation task showed that the strength of the illusion was modulated by the $\gamma$ angle value. The angular error increased as the $\gamma$ angle increased up to a value of $90^{\circ}$. Corresponding mean angular errors were $0.889^{\circ}$ (angle $\gamma=45^{\circ}$ ), $1.487^{\circ}\left(\right.$ angle $\gamma=67.5^{\circ}$ ) and $2.696^{\circ}$ (angle $\gamma$ $\left.=90^{\circ}\right)$. Beyond $90^{\circ}$, the angular error decreased from $1.947^{\circ}$ (angle $\gamma=112.5^{\circ}$ ) to $1.209^{\circ}$ (angle $\gamma=135^{\circ}$ ).

This finding was supported by a repeated-measures ANOVA. Results revealed a significant effect of the $\gamma$ angle

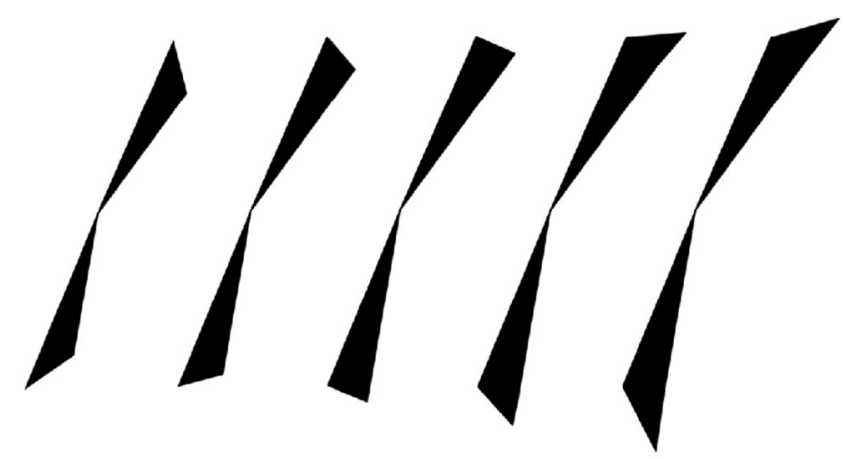
(a)
(b)
(c)
(d)
(e)

Fig. 3 Stimulus figures used in Experiment 2. Here, five different angle $\gamma$ values were used: $45^{\circ}(\mathbf{a}), 67.5^{\circ}(\mathbf{b}), 90^{\circ}(\mathbf{c}), 112.5^{\circ}(\mathbf{d})$, and $135^{\circ}(\mathbf{e})$ 


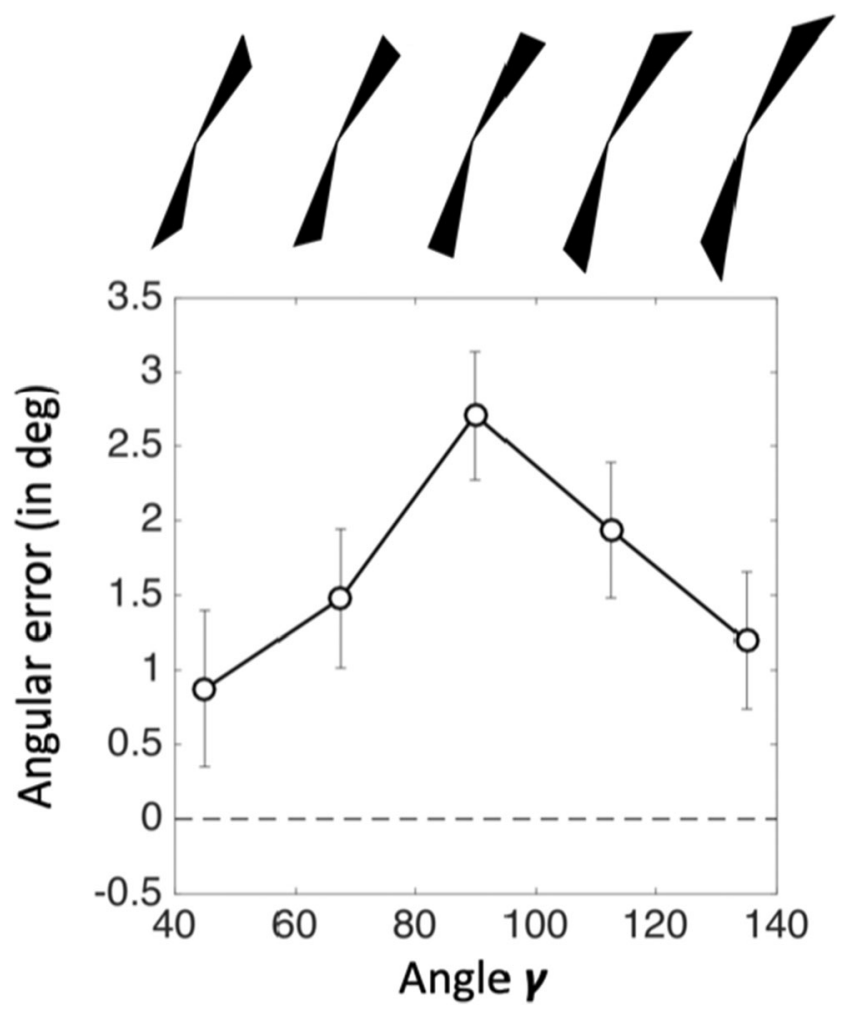

Fig. 4 Cancellation adjustments plotted as a function of angle $\gamma$ values (Experiment 2). Error bars are \pm 1 SEM

value $\left(45^{\circ} \times 67.5^{\circ} \times 90^{\circ} \times 112.5^{\circ} \times 135^{\circ}\right), F(4,792)=68.519$, $p<.001 ; \eta_{\mathrm{G}}^{2}=0.084, \eta_{\mathrm{p}}^{2}=0.257$. A post hoc paired $t$ test (with Holm-Bonferroni correction) revealed a significant difference between all $\gamma$ angle conditions, these multiple comparisons are shown in Table 2. We concluded that the Bourdon illusion is strongest when the $\gamma$ angle is equal to $90^{\circ}$ (i.e., corresponding to a right-angled triangle).

\section{Experiment 3}

\section{Methods}

\section{Observers}

We recruited 19 different psychology undergraduates aged 19-25 years as observers. All had normal or corrected-tonormal vision and were naïve to the purpose of the experiment. This third experiment was conducted in accordance with the Declaration of Helsinki.

\section{Apparatus}

The apparatus was identical to that used in Experiment 1.

\section{Stimuli}

Figures were composed of two right-angled triangles connected by their apices. These triangles were displayed in black ( $\mathrm{x}=$ $\left.0.30, \mathrm{y}=0.45 ; \mathrm{Y}=1.03 \mathrm{~cd} / \mathrm{m}^{2}\right)$ against a neutral gray background $\left(\mathrm{x}=0.29, \mathrm{y}=0.32 ; \mathrm{Y}=60.32 \mathrm{~cd} / \mathrm{m}^{2}\right)$. The apex angle was systematically $12.5^{\circ}$ (see angle $\beta$ in Fig. 1), and the vertical orientation of the figure was $22.5^{\circ}$ (angle $\alpha$ in Fig. 1). These values had produced the strongest illusions in previous studies (Rozvany \& Day, 1980; Verstijnen \& van Leeuwen, 1998).

Figure 5 shows the stimuli used in this experiment. The patterns were created by varying the size of one right-angled triangle while holding the size of the second right-angled triangle constant. Each of the two right-angled triangles was displayed in four versions of varying size. For the triangle that varied in size, the $\mathrm{AB}$ (or $\mathrm{BC}$ ) lengths corresponded to the distance of A (or C) from the central apex (see Fig. 1b) and

Table 2 Summary of multiple comparisons in Experiment 2

\begin{tabular}{|c|c|c|c|c|c|c|c|c|}
\hline \multirow{2}{*}{$\begin{array}{l}\text { Comparison } \\
\text { angle } \gamma\end{array}$} & & & & & & & & \\
\hline & & angle $\gamma$ & Mean difference & SE & $\mathrm{df}$ & $\mathrm{t}$ & Cohen's d & $\begin{array}{l}\mathrm{p}_{\text {Holm- }} \\
\text { Bonferron }\end{array}$ \\
\hline \multirow[t]{4}{*}{$45^{\circ}$} & - & $67.5^{\circ}$ & -0.604 & 0.1194 & 199 & -5.06 & -0.353 & $<.001$ \\
\hline & - & $90^{\circ}$ & -1.831 & 0.1501 & 199 & -12.20 & -1.065 & $<.001$ \\
\hline & - & $112.5^{\circ}$ & -1.062 & 0.1424 & 199 & -7.46 & -0.624 & $<.001$ \\
\hline & - & $135^{\circ}$ & -0.324 & 0.1411 & 199 & -2.29 & -0.189 & 0.023 \\
\hline \multirow[t]{3}{*}{$67.5^{\circ}$} & - & $90^{\circ}$ & -1.227 & 0.1163 & 199 & -10.55 & -0.712 & $<.001$ \\
\hline & - & $112.5^{\circ}$ & -0.457 & 0.1080 & 199 & -4.23 & -0.271 & $<.001$ \\
\hline & - & $135^{\circ}$ & 0.281 & 0.1058 & 199 & 2.65 & 0.164 & 0.017 \\
\hline \multirow[t]{2}{*}{$90^{\circ}$} & - & $112.5^{\circ}$ & 0.770 & 0.0912 & 199 & 8.43 & 0.442 & $<.001$ \\
\hline & - & $135^{\circ}$ & 1.507 & 0.1174 & 199 & 12.84 & 0.876 & $<.001$ \\
\hline $112.5^{\circ}$ & - & $135^{\circ}$ & 0.738 & 0.0976 & 199 & 7.55 & 0.435 & $<.001$ \\
\hline
\end{tabular}




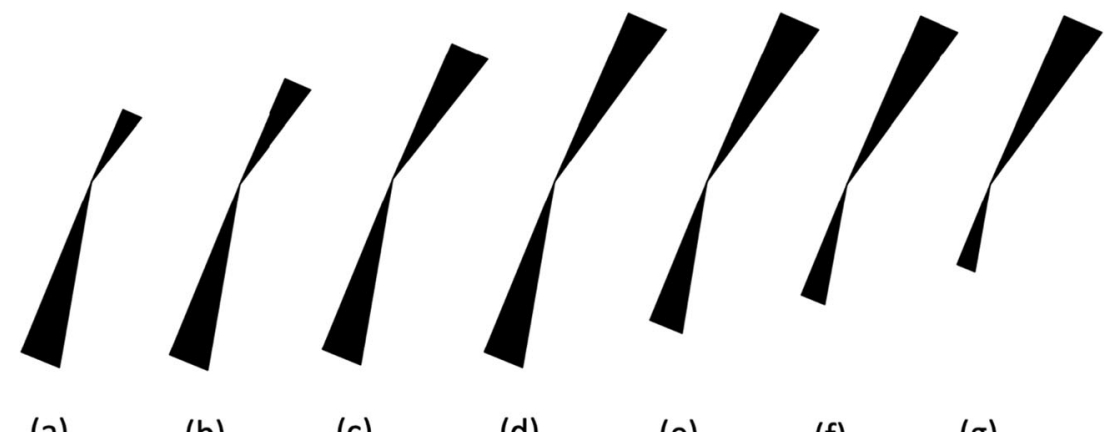

(a)

(b)

(c)

(d)

Fig. 5 Stimuli used in Experiment 3. a-c In three patterns, the rightangled triangle at the top was smaller than the right-angled triangle at the bottom. d Classic Bourdon figure in which the two right-angled

were approximately $8.6^{\circ}, 6.4^{\circ}, 4.2^{\circ}$, and $2.1^{\circ}$, while the $\mathrm{AD}$ (or CE) lengths (see Fig. 1b) were $2.4^{\circ}, 1.8^{\circ}, 1.2^{\circ}$, and $0.6^{\circ}$. For the triangle that stayed the same size, the $\mathrm{AB}$ (or $\mathrm{BC}$ ) length was approximately $8.6^{\circ}$ and the $\mathrm{AD}$ (or $\mathrm{CE}$ ) length was around $2.4^{\circ}$. It should be noted that in one condition, the two right-angled triangles were the same size. There were seven different conditions.

\section{Procedure}

The procedure was identical to that used in the two previous experiments. There were $3 \mathrm{~min}$ of screen adaptation prior to testing. Each observer performed ten trials in each condition, making a total of 70 trials. Practice trials preceded the data collection. The order of the trials was randomized for each observer.

\section{Results}

For each observer, the strength of the illusion was measured as the angular error, obtained by computing the difference between the cancellation adjustment and the coordinates of the AC line (see Fig. 1b). Mean angular errors for all seven conditions are shown in Fig. 6. The angular error increased as the distance of $\mathrm{C}$ from the central apex increased: gradually at first (angular error of $1.572^{\circ}$ at $\left.2.1^{\circ}\right)$, then levelling off $\left(1.884^{\circ}-1.845^{\circ}\right.$ between $4.2^{\circ}$ and $6.4^{\circ}$ ), before rising steeply $\left(2.674^{\circ}\right.$ at $8.6^{\circ}$ ). The angular error decreased as the distance of A from the central apex decreased: steeply at first (angular error of $2.674^{\circ}$ at $8.6^{\circ}$ ), then levelling off $\left(1.443^{\circ}-1.263^{\circ}\right.$ between $4.2^{\circ}$ and $\left.6.4^{\circ}\right)$, before gradually decreasing $\left(0.754^{\circ}\right.$ at $\left.2.1^{\circ}\right)$.

A repeated-measures ANOVA assessed significant differences in illusion strength across conditions, $F(6$, $1128)=53.940, p<.001 ; \eta_{\mathrm{G}}^{2}=0.162, \eta_{\mathrm{p}}^{2}=0.223$. A Holm-Bonferroni post hoc test revealed significant differences between the condition where $\mathrm{A}$ and $\mathrm{C}$ were the same distance from the central apex and all other triangles are of equal size. $\mathbf{e}-\mathbf{g}$ In three patterns, the right-angled triangle at the bottom was smaller than the right-angled triangle at the top

conditions as shown in Table 3 (Holm-Bonferroni correction, all $p \mathrm{~s}<.001)$. Comparisons between the conditions where the distance of $\mathrm{C}$ (or $\mathrm{A}$ ) from the central apex was either $4.2^{\circ}$ or $6.4^{\circ}$ were not significant. All other comparisons were significant (Holm-Bonferroni correction, all $p \mathrm{~s}<.05)$. We conclude that the Bourdon illusion is strongest when the two triangles are of equal size.
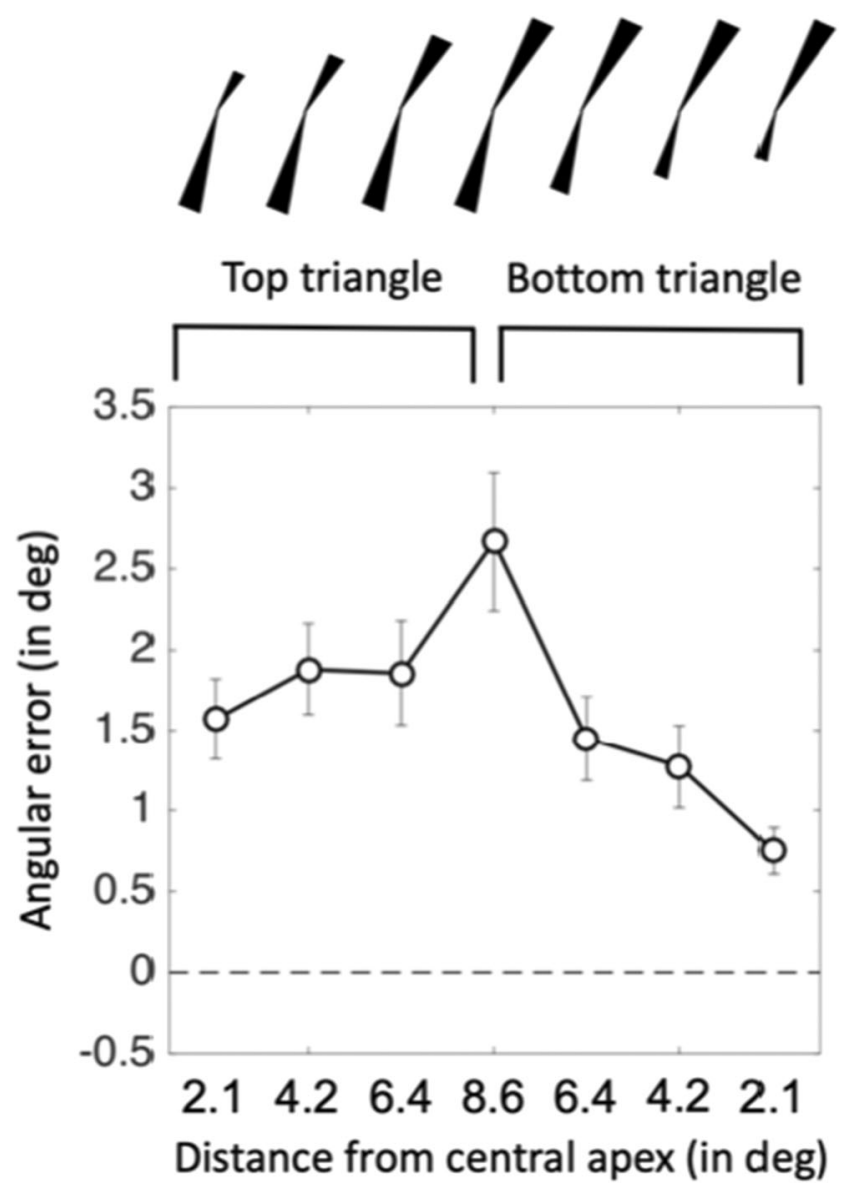

Fig. 6 Mean adjustments made to cancel the Bourdon illusion as a function of the distance of A (bottom triangle) or C (top triangle) from the central apex (Experiment 3). Error bars are \pm 1 SEM 
Table 3 Summary of multiple comparisons in Experiment 3

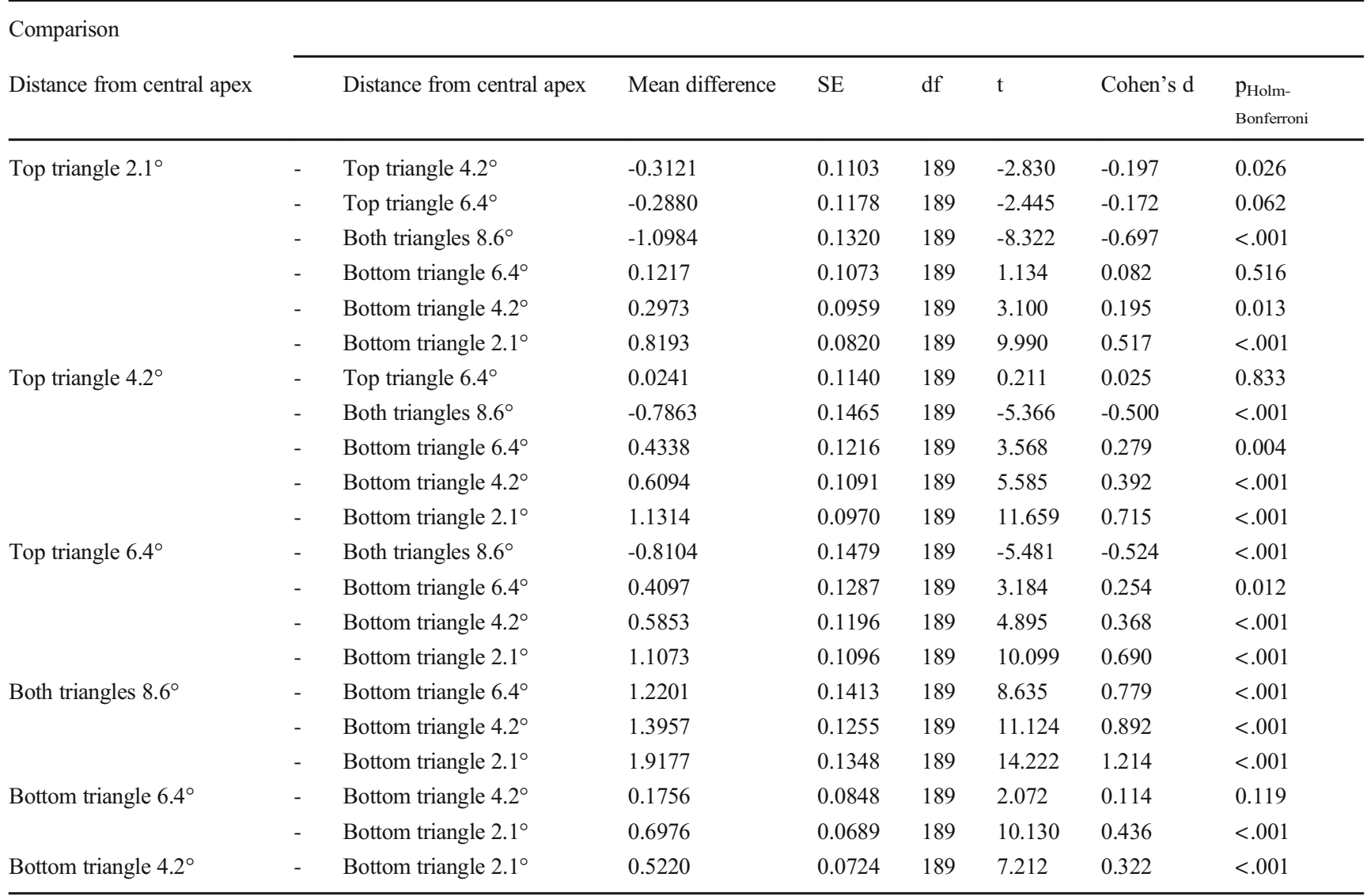

\section{Discussion}

\section{Summary of results}

Our experiments were designed to test the effect of shape arrangement on the strength of the Bourdon illusion. A cancellation method was used for quantification. In this task, observers simultaneously adjusted two sides ( $\mathrm{AB}$ and $\mathrm{BC}$ in Fig. 1) until they appeared straight. Results demonstrated that triangle shape plays a critical role in inducing the illusion. In Experiment 1, the strongest Bourdon illusion occurred when the internal apical angle $(\beta)$ was around $12^{\circ}$. The second experiment showed that the illusion was stronger for right-angled triangles, and weaker when the right angles were replaced by acute or obtuse ones. Finally, Experiment 3 indicated that the strongest Bourdon illusion occurs when the two triangles are the same size. These findings show that the use of the triangle shape is crucial for creating the Bourdon illusion, and suggest that the right-angled triangle is the predominant figural determinant for cancellation adjustments.

\section{Comparison with previous studies}

The first experiment indicated that the greatest angular error was for an internal apical angle of $12^{\circ}$, consistent with previous findings (Rozvany \& Day, 1980). In our first experiment, this angular error was $1.83^{\circ}$, and in the two subsequent experiments where the value of angle $\beta$ was held constant at $12.5^{\circ}$, the maximum angular errors were $2.696^{\circ}$ and $2.674^{\circ}$. These values are similar to those found in previous studies when authors used similar displays to create the Bourdon illusion (3-4 in Rozvany \& Day, 1980; 2-4 ${ }^{\circ}$ in Verstijnen \& van Leeuwen, $1998 ; 3.75^{\circ}$ in Walker \& Shank, $1987 ; 1-2^{\circ}$ in Wenderoth et al., 1986; $2^{\circ}$ in Wenderoth \& O'Connor, $1987 b)$. We interpret these results to mean that an angle $\beta$ of $12.5^{\circ}$ contributes to a robust Bourdon illusion.

There is nonetheless considerable variability between studies. One possible explanation is that there are differences in the methods adopted to collect the data and in the apparatuses used. Verstijnen and van Leeuwen (1998) reported three different tasks in which the Bourdon illusion was studied in different orientations while the inner apical angle was held constant at $12.5^{\circ}$. Results showed that the strength of the 
Bourdon illusion varied according to the task. When the pattern had an orientation of $22.5^{\circ}$, authors found a mean angular error of around $2-3^{\circ}$ for a multiple-choice task and a construction task, and $3-4^{\circ}$ for an adjustment procedure. In the present study, we used a cancellation task that had not previously been administered, which may explain why our results differed.

In the first experiment, results indicated that the Bourdon illusion was stronger when scalene triangles were used rather than isosceles triangles (e.g., angle $\beta$ equal to $45^{\circ}$ ). These data were consistent with previous studies using an angle discrimination task, in which performances on angles forming an isosceles triangle were more precise than those forming a scalene triangle (Kennedy et al., 2006, 2008). Increasing angle $\beta$ may conceivably have reduced the strength of the illusion because the salience of the apical angle increased. When the apical angles were well discriminated, observers correctly dissociated the collinear $(\mathrm{AB}$ and $\mathrm{BC}$ in Fig. 1) edges from the hypotenuse (BE and BD in Fig. 1). Consequently, the use of isosceles triangles reduces and even cancels the Bourdon illusion.

Our second experiment showed that scalene triangles did not produce the same effect, indicating that the angle $\gamma$ values influenced the strength of the Bourdon illusion. These results suggest that angles $\beta$ and $\gamma$ interact to create the illusion. Right angles are easily perceptible, whereas acute angles tend to be overestimated, and obtuse angles underestimated (Chen \& Levi, 1996; Nundy et al., 2000). Thus, the use of a right angle does not change the perception of angle $\beta$, and maximizes the illusion. By contrast, the perception of angle $\beta$ is modulated by acute or obtuse angles. The illusion is therefore weaker, consistent with our psychophysical results.

Our data indicated that the strongest Bourdon illusion occurred when the triangles were of equal size (Exp. 3). This result suggests that increasing the visibility of the symmetrical display increases the illusion. These data are consistent with those reported in previous studies showing that an unbalanced pattern decreases the strength of many visual illusions. For instance, changes at the intersection between oblique and parallel lines on one side of the Poggendorff illusion reduce the misalignment phenomenon (Day, 1988). Similarly, the strength of the Zöllner illusion decreases when the inner or outer parts of the oblique lines are removed (Oyama, 1975).

\section{Previous explanations for the Bourdon illusion}

Various explanations for the Bourdon illusion have been put forward. Walker and Shank $(1987,1988$ a) developed a model based on interactions between orientation-selective neurons. For these authors, there are no interactions when two lines have very different orientations. By contrast, when two lines have similar orientations, they mutually induce a specific neural distribution. This results in a peak of firing from the summation of lateral inhibition from the edges with the neural excitation from the solid figure, resulting in a mutual attraction effect.

According to another explanation put forward by Wenderoth et al. (1986) (see also Wenderoth, 1991), every stimulus is processed along three separate neural channels coding orientation, position, and collinearity. These authors postulated that the illusion arises from conflicting signals between these channels. Under normal circumstances, the neural signals are not in conflict, but this is not the case with the Bourdon edges (lines $\mathrm{AB}$ and $\mathrm{BC}$ in Fig. 1a), and so a neural compromise occurs. The Bourdon illusion involves a failure to dissociate the orientation of the collinear edges (e.g., $\mathrm{AB}$ and $\mathrm{BC}$ in Fig. 1) from the orientations and positions of the hypotenuse edges (e.g., BD and BE in Fig. 1). This failure results in the collinear edges being attracted in the direction induced by the hypotenuse edges.

Finally, Day $(1989,1990)$ suggested that multiple cues define a visual pattern. When these cues are in conflict, the perception is a compromise between them. In the Bourdon illusion, the collinear edges have one specific orientation, and each hypotenuse edge has a different one. The compromise between these orientations results in the collinear edges being perceived to follow the direction of the hypotenuse edges.

According to these models, the collinear and hypotenuse edges combine to explain the Bourdon illusion, albeit via different mechanisms. However, they fail to consider other figural parameters. Our data suggest that the use of right-angled triangles generates a stronger illusion, and thus increases the angular error (Exp. 2). Furthermore, our angular error analysis showed that the strongest illusion occurred when the right-angled triangles were of equal size (Exp. 3).

The present study suggests that the Bourdon illusion arises from a combination of configural processing. It is constructed by integrating multiple sources of information, including the object's geometric properties. Thus, models such as those described above should be extended to take the different figural parameters into account.

\section{Role of inhibitory processes}

The Bourdon illusion can be classified as an illusion of orientation, the effects of which are associated with misalignment or nonparallelism (Day, 2010; Hamburger et al., 2017). This type of illusion has different stimulus properties, but the oblique factor is a common condition (Day, 2010).

Rozvany and Day (1980) noted that the Bourdon illusion is stronger when the figures are oblique, rather than vertical or horizontal, as is the case with the Zöllner (Parlangeli \& 
Roncato, 1995; White, 1975), Poggendorff (Day \& Dickinson, 1976; Weintraub et al., 1980), and tilt (Clifford, 2014; Clifford et al., 2000) illusions. These illusions are weaker when the figures are vertical or horizontal. These illusions and the Bourdon illusion may conceivably share common mechanisms.

One classic explanation is that these illusions stem from neural inhibitory processes (Gillam, 2017; Westheimer, 2008). It is well known that any given orientation is coded by neurons sensitive to a range of orientations. The illusion is attributed to the fact that a bias is introduced by lateral inhibition between neighboring orientation channels (Blakemore et al., 1970; Blakemore \& Tobin, 1972; Carpenter \& Blakemore, 1973).

Lateral inhibition was also a central aspect of Walker and Shank's $(1987,1988$ a) theory explaining the Bourdon illusion. However, Wenderoth et al. (1990) noted that this explanation holds good not only for a two-triangle display such as that in the original Bourdon figure, but also for a single-triangle display. The role of lateral inhibition has also been disputed in other phenomena. For example, Gillam (2017) discussed the role of lateral inhibition because the illusion persists when the original lines are replaced by subjective contours. It is still present when the parallel lines are replaced by empty interspaces in the Zöllner illusion (Earle \& Maskell, 1995) or by dots in the Wundt-Hering illusion (Coren, 1970). This has also been observed for other figures using subjective contours, such as the Poggendorff (Gregory, 1972; Tibber et al., 2008) and Bourdon (Walker \& Shank, 1987, 1988a, 1988b) illusions, indicating that physical angles and lateral inhibition processes are not necessary because the illusion persists.

Nonetheless, Seymour et al. (2018) confirmed the inhibition of cortical responses, by performing functional neuroimaging of area V1 of the human visual cortex during the perception of the tilt illusion. Results showed that participants who exhibited strong neural suppression perceived a stronger illusory effect. This could be the result of lateral inhibition, but feedback projections from extrastriate cortical areas may also be involved. This is a relevant idea, in view of studies suggesting that feedback signals play an important role in the perception of Kanisza shapes (Kok et al., 2016; Kok \& de Lange, 2014). Feedback projections have been ignored in previous theories, even though they are just as numerous as feedforward projections in the visual cortex (Markov et al., 2014).

The present study shows that figural parameters modulate the Bourdon illusion. Taken together, our data support the hypothesis that the mechanisms underlying the distortions in contour perception involve multiple levels of processing. It would be interesting for future research to clarify the role of feedforward, feedback, and lateral processes in orientation illusions.
Data availability The materials created and used for this study have been described in the article. The data obtained during this study have been reported in the article along with figures and tables. Any additional information, materials, and datasets are available from the corresponding author.

\section{References}

Blakemore, C., \& Tobin, E. A. (1972). Lateral inhibition between orientation detectors in the cat's visual cortex. Experimental Brain Research, 15, 439-440.

Blakemore, C., Carpenter, B. R. H. S., \& Georgeson, M. A. (1970). Lateral inhibition between orientation detectors in the human visual system. Nature, 228, 37-39.

Bourdon, B. (1902). La perception visuelle de l'espace. Schleicher Frères.

Carpenter, R. H. S., \& Blakemore, C. (1973). Interactions between orientations in human vision. Experimental Brain Research, 18, 287303.

Chen, S., \& Levi, D. M. (1996). Angle judgement: Is the whole the sum of its parts? Vision Research, 36(12), 1721-1735.

Clifford, C. (2014). The tilt illusion: Phenomenology and functional implications. Vision Research, 104, 3-11.

Clifford, C., Wenderoth, P., \& Spehar, B. (2000). A functional angle on some after-effects in cortical vision. Proceedings of the Royal Society B: Biological Sciences, 267(1454), 1705-1710.

Coren, S. (1970). Lateral inhibition and the Wundt-Hering illusion. Psychonomic Science, 18(6), 341.

Day, R. H. (1988). Reduction and elimination of the Poggendorff misalignment effect by minor changes at intersections: Implications for the perceptual-compromise explanation. Psychological Research, 50, 7-11.

Day, R. H. (1989). Natural and artificial cues, perceptual compromise and the basis of veridical and illusory perception. In D. Vickers \& P. L. Smith (Eds.), Human information processing: Mechanisms and models (pp. 107-129). : Elsevier.

Day, R. H. (1990). The Bourdon illusion in haptic space. Perception \& Psychophysics, 47(4), 400-404.

Day, R. H. (2010). On the common stimulus condition and explanation of the Müller-Lyer, Poggendorff and Zöllner illusions: The basis for a class of geometrical illusions. Autralian Journal of Psychology, 62, 115-120.

Day, R. H., \& Dickinson, R. G. (1976). The components of the Poggendorff illusion. British Journal of Psychology, 67(4), 537552.

Day, R. H., Mitchell, P., \& Stecher, E. J. (1990). The Bourdon illusion occurs with straight-, right-angle-, and parallel-edge figures. Perception \& Psychophysics, 48(4), 375-381.

Earle, D. C., \& Maskell, S. J. (1995). Spatial filtering and the ZöllnerJudd geometrical illusion: Further studies. Perception, 24(12), 13971406.

Gillam, B. (2017). An analysis of theoretical approaches to geometricaloptical illusions. In A. Shapiro \& D. Todorovic (Eds.), The Oxford compendium of visual illusions (pp. 64-73). Oxford University Press.

Gregory, R. L. (1972). Cognitive contours. Nature, 238, 51-52.

Hamburger, K., Hansen, T., \& Gegenfurtner, K. (2017). Geometricoptical illusions under isoluminance? In A. Shapiro \& D. Todorovic (Eds.), The Oxford compendium of visual illusions (pp. 206-208). Oxford University Press.

Kennedy, G. J., Orbach, H. S., \& Loffler, G. (2006). Effects of global shape on angle discrimination. Vision Research, 46, 1530-1539. 
Kennedy, G. J., Orbach, H. S., \& Loffler, G. (2008). Global shape versus local feature: An angle illusion. Vision Research, 48, 1281-1289.

Kok, P., \& de Lange, F. P. (2014). Shape perception simultaneously upand downregulates neural activity in the primary visual cortex. Current Biology, 24(13), 1531-1535.

Kok, P., Bains, L. J., van Mourik, T., Norris, D. G., \& de Lange, F. P. (2016). Selective activation of the deep layers of the human primary visual cortex by top-down feedback. Current Biology, 26(3), 371376.

Markov, N.T., Vezoli, J., Chameau, P., Falchier, A., Quilodran, R., Huissoud, C., Lamy, C., Misery, P., Giroud, P., Ullman, S., Barone, P., Dehay, C., Knoblauch, K., \& Kennedy, H. (2014). Anatomy of hierarchy: Feedforward and feedback pathways in macaque visual cortex. The Journal of Comparative Neurology, 522(1), 225-259.

Nundy, S., Lotto, B., Coppola, D., Shimpi, A., \& Purves, D. (2000). Why are angles misperceived? Proceedings of National Academy of Science USA, 97, 5592-5597.

Oyama, T. (1975). Determinants of the Zöllner illusion. Psychological Research, 37, 261-280.

Parlangeli, O., \& Roncato, S. (1995). The global figural characteristics in the Zöllner illusion. Perception, 24, 501-512.

Rozvany, G. I. N., \& Day, R. H. (1980). Determinants of the Bourdon effect. Perception \& Psychophysics, 28(1), 39-44.

Seymour, K. J., Stein, T., Clifford, C. W. G., \& Sterzer, P. (2018). Cortical suppression in human primary visual cortex predicts individual differences in illusory tilt perception. Journal of Vision, 18(11), 1-10.

Tibber, M. S., Melmoth, D. R., \& Morgan, M. J. (2008). Biases and sensitivities in the Poggendorff effect when driven by subjective contours. Investigative Ophthalmology and Vision Science, 49(1), 474-478.

Verstijnen, I. M., \& van Leeuwen, C. (1998). Anomalous orientation effects in the Bourdon illusion. Psychonomic Bulletin \& Review, 5(2), 290-294.
Walker, J. T., \& Shank, M. D. (1987). The Bourdon illusion in subjective contours. Perception \& Psychophysics, 42(1), 15-24.

Walker, J. T., \& Shank, M. D. (1988a). Real and subjective lines and edges in the Bourdon illusion. Perception \& Psychophysics, 43(5), 475-484.

Walker, J. T., \& Shank, M. D. (1988b). Interactions between real and subjective contours in the Bourdon illusion. Perception \& Psychophysics, 43(6), 567-574.

Weintraub, D. J., Krantz, D. H., \& Olson, T. P. (1980). The Poggendorff illusion: Consider all the angles. Journal of Experimental Psychology: Human, Perception and Performance, 6(4), 718-725.

Wenderoth, P. (1991). The basis of the Bourdon illusion. Perception \& Psychophysics, 49(4), 393-397.

Wenderoth, P., \& O'Connor, T. (1987a). Outline- and solid-angle orientation illusions have different determinants. Perception \& Psychophysics, 41(1), 45-52.

Wenderoth, P., \& O'Connor, T. (1987b). The effects of display and observer strategy variables on Bourdon assimilation illusions. Perception, 16, 79-88.

Wenderoth, P., Criss, G., \& van der Zwan, R. (1990). Determinants of subjective contour: Bourdon illusions and "unbending" effects. Perception \& Psychophysics, 48(5), 497-508.

Wenderoth, P., O'Connor, T., \& Johnson, M. (1986). Expansion and contraction of outline and solid acute angles: Effects of angle magnitude, type of display, and the nature of the matching task. Perception \& Psychophysics, 39(4), 261-266.

Westheimer, G. (2008). Illusions in the spatial sense of the eye: Geometrical-optical illusions and the neural representation of space. Vision Research, 48, 2128-2142.

White, K. G. (1975). Orientation effects on contour interaction in the Zöllner illusion. Perception \& Psychophysics, 17(4), 387-392.

Publisher's note Springer Nature remains neutral with regard to jurisdictional claims in published maps and institutional affiliations. 